\title{
ACESSIBILIDADE E EDUCAÇÃO INFANTIL: O PROCESSO DE INCLUSÃO DO PÚBLICO-ALVO DA EDUCAÇÃO ESPECIAL EM MANAUS/AM
}

\author{
ACCESIBILIDAD Y EDUCACIÓN INFANTIL: EL PROCESO DE INCLUSIÓN DEL \\ PÚBLICO-PUNTO DE EDUCACIÓN ESPECIAL EN MANAUS/AM
}

\section{ACCESSIBILITY AND CHILD EDUCATION: THE PROCESS OF INCLUSION OF TARGET AUDIENCE OF SPECIAL EDUCATION IN MANAUS/AM}

\author{
Maria Almerinda de Souza MATOS ${ }^{1}$ \\ Danilo Batista de SOUZA ${ }^{2}$ \\ Jáima Pinheiro de OLIVEIRA ${ }^{3}$
}

RESUMO: Apresentamos neste trabalho discussões sobre o processo de inclusão do públicoalvo da Educação Especial na Educação Infantil em Manaus (AM), com ênfase na situação da acessibilidade. Para isso, apresentamos dados de alunos incluídos nas escolas da Secretaria Municipal de Educação de Manaus e exemplificamos a condição da acessibilidade em duas escolas. Assim, defendemos que a escola possui um papel importante, pois é um dos primeiros espaços de vivência pública da criança. No contexto da inclusão e do desenho universal espera-se que os espaços escolares sejam construídos levando em conta a sua possibilidade de utilização por todos os alunos.

PALAVRAS-CHAVE: Acessibilidade. Educação infantil. Inclusão escolar.

RESUMEN: En este trabajo se presentan discusiones sobre el proceso de inclusión del público objetivo de la Educación Especial en la Educación Infantil en Manaus (AM), con énfasis en la situación de la accesibilidad. Para ello, presentamos datos de alumnos incluidos en las escuelas de la Secretaría Municipal de Educación de Manaus y ejemplificamos la condición de la accesibilidad en dos escuelas. Así, defendemos que la escuela tiene un papel importante, pues es uno de los primeros espacios de vivencia pública del niño. En el contexto de la inclusión y del diseño universal se espera que los espacios escolares sean construidos teniendo en cuenta su posibilidad de utilización por todos los alumnos.

PALABRAS CLAVE: Accesibilidad. Educación Infantil. Inclusión escolar.

\footnotetext{
${ }^{1}$ Universidade Federal do Amazonas (UFAM), Manaus - AM - Brasil. Professora Associada, Departamento de Teorias e Fundamentos (DTF/FACED). ORCID: <https://orcid.org/0000-0002-4776-2155>. E-mail: profalmerinda@hotmail.com

${ }^{2}$ Universidade Federal do Amazonas (UFAM), Manaus - AM - Brasil. Doutorando, Programa de PósGraduação em Educação (PPGE/FACED). ORCID: <https://orcid.org/0000-0001-6017-3614>. E-mail: danilo_batista_14@hotmail.com

${ }^{3}$ Universidade Estadual Paulista (UNESP), Marília - SP - Brasil. Professora Assistente, Departamento de Educação Especial (FFC/UNESP). ORCID: <https://orcid.org/0000-0002-0156-3804>. E-mail: jaima@marilia.unesp.br
} 
ABSTRACT: We present in this work discussions about the process of inclusion of the target audience of Special Education in Early Childhood Education in Manaus (AM), with emphasis on the accessibility situation. For this, we present data of students included in the schools of the Municipal Education Department of Manaus and we exemplify the condition of accessibility in two schools. Thus, we defend that the school plays an important role, since it is one of the first spaces of public experience of the child. In the context of inclusion and universal design it is expected that school spaces will be constructed taking into account the possibility of their use by all students.

KEYWORDS: Accessibility. Child education. School inclusion.

\section{Introdução}

A inserção da educação infantil na educação básica, como sua primeira etapa, é o reconhecimento de que a educação começa nos primeiros anos de vida e é essencial para o cumprimento de sua finalidade, ou seja, a educação básica tem por finalidade desenvolver o educando, assegurando a formação comum indispensável para o exercício da cidadania e fornecendo meios para progredir no trabalho e nos estudos posteriores.

No Censo Escolar da Educação Básica de 2016 (INEP, 2017), o percentual de alunos com deficiências, transtornos globais do desenvolvimento ou altas habilidades/superdotação incluídos em escolas comuns foi de 57,8\%. Comparando com o dado de 2008, que foi de $31 \%$, percebemos um aumento significativo a partir do ano de implementação da Política Nacional de Educação Especial na Perspectiva da Educação Inclusiva (BRASIL, 2008).

Tendo como referência o ano de 2008 até o ano de 2016, o número de escolas que oferecem creche cresceu 56,9\%, ou seja, 64.552 escolas ofertam a creche, já as que ofertam a Pré-Escola são 105.324. Dessas escolas, apenas 24,6\% das creches e 23,3\% das escolas que ofertam a Pré-Escola têm seus espaços e vias adequados para que os alunos com deficiência e mobilidade os utilizem com segurança e autonomia (INEP, 2017).

Com as discussões sobre inclusão educacional dos alunos com deficiências, transtornos globais do desenvolvimento ou altas habilidades/superdotação nas escolas públicas, esperamos que mais profissionais lutem por uma escola inclusiva e que defendam o cumprimento das políticas públicas inclusivas.

Neste estudo utilizamos a abordagem qualitativa, a pesquisa bibliográfica e documental para discutir a acessibilidade e a Educação Infantil no processo de inclusão do público-alvo da Educação Especial na Perspectiva da Educação Inclusiva em Manaus/AM. 
A partir da pesquisa bibliográfica, também denominada de pesquisa de fontes secundárias (MARCONI; LAKATOS, 1993), procuramos realizar um apanhado da literatura existente, principalmente em livros, com o intuito de nos fornecer dados atuais e significativos a respeito de acessibilidade, Educação Infantil e inclusão dos alunos com deficiências, transtornos globais do desenvolvimento e altas habilidades/superdotação.

Para recolha das informações, realizamos a pesquisa documental por meio dos Pareceres Técnicos com as matrículas de educandos com deficiências, transtornos globais do desenvolvimento ou altas habilidades/superdotação na Secretaria Municipal de Educação de Manaus (SEMED/Manaus). De acordo com Lüdke e André (1986), os dados adquiridos por diversos procedimentos metodológicos desvelam aspectos novos de um problema ou de um tema.

A análise formal dos dados foi desenvolvida a partir do que propõe a análise de conteúdo, que tem sido muito utilizada em pesquisas do tipo qualitativa (TRIVIÑOS, 1987; MINAYO, 1993; ANDRÉ, 1995). Essa técnica permite uma análise mais refinada do que foi coletado, capturando o dito e não dito das interações com os documentos.

Segundo Bardin (2011), a análise de conteúdo em uma investigação qualitativa presume averiguar a existência ou falta de uma propriedade de conteúdo ou de parte da ideia sobre um assunto escolhido.

A universidade (comunidade acadêmica) precisa estar cada vez mais preparada, no sentido de construir ambientes favoráveis ao processo de inclusão de alunos com deficiência e/ou mobilidade reduzida na educação infantil, da mesma maneira que a sociedade deve compreendê-los na qualidade de indivíduos com as mesmas garantias, benefícios e deveres assegurados por lei, com inclusão à uma educação que possibilite o acesso, qualidade e permanência na escola.

\section{Aspectos Fundamentais sobre a Educação Infantil}

A ideia de infância não existiu sempre, e nem da mesma maneira. Ela aparece com a sociedade capitalista, na medida em que mudam a inserção e o papel social da criança na comunidade.

As crianças possuem diversas características que as diferenciam entre si. Podem ser meninos ou meninas; negros, amarelos, brancos; surdas ou ouvintes; alegres ou quietas. Podem viver na cidade ou no campo, no litoral, na floresta ou na região ribeirinha (BRASIL, 2009, p. 23). 
A concepção de criança que adotamos considera-a como um sujeito histórico, que nasce num tempo, numa classe social e num determinado contexto sociocultural. Sendo assim, ela não pode ser um cidadão do futuro se não a concebermos como um sujeito no presente. $\mathrm{O}$ conceito de infância, nesse sentido, traduz-se no mundo presente, dos direitos, dos desejos, das opções e da mudança, sendo a criança não uma espectadora desse tempo, mas um sujeito ativo do processo (KRAMER, 1999, p. 85).

Em décadas passadas, as políticas públicas para a Educação Infantil se caracterizaram por projetos assistencialistas, distantes de ações que valorizassem a educação, ao passo que, hoje, surge uma nova mentalidade em relação ao significado de Educação Infantil. Desta forma, Kramer (1999, p. 154) destaca que "a educação infantil passa a ser entendida não mais como assistência e caridade para as crianças pobres, mas, sim, como um espaço educacional e de formação para a cidadania".

No sistema educacional brasileiro, a Educação Básica é composta por três blocos de formação: a Educação Infantil, o ensino fundamental e o ensino médio. $\mathrm{O}$ atendimento de crianças de zero a cinco anos em creches e pré-escola constitui direito assegurado pela Constituição Federal de 1988 (BRASIL, 1988), através do Art. 208, inciso IV, e consolidado pela Lei de Diretrizes e Bases da Educação Nacional - LDB n. 9394/96 (BRASIL, 1996), que estabelece:

Art. 29 - A educação infantil, primeira etapa da educação básica, tem como finalidade o desenvolvimento integral da criança até seis anos de idade, em seus aspectos físico, psicológico, intelectual e social, complementando a ação da família e da comunidade.

De tal modo, é necessário articular o debate sobre o significado da educação das crianças pequenas em estabelecimentos educacionais e suas práticas para, assim, permitir que as ideias e as ações oriundas das secretarias possam colaborar e potencializar a Educação Infantil. Nessa linha,

A promoção dos direitos das crianças à educação e à infância começa a ser efetivada desde a defesa de princípios como a equidade e a qualidade no atendimento até a definição da proposta pedagógica dos estabelecimentos de educação infantil (BRASIL, 2009, p. 21).

Atualmente, a Educação Infantil vem sendo pensada pelo poder público federal ligada à função educativa, levando-se em conta a formação da criança. Assim, aos poucos, a Educação Infantil passou a ser entendida por nós como um processo que tem a história da 
criança associada a um conhecimento crítico e autônomo favorecedor da transformação do contexto social (KRAMER, 1999, p. 229).

Ao realizar um estudo sobre as políticas destinadas à Educação Infantil, Kramer (1999) sintetiza os aspectos referentes à criação das instituições ligadas a esse nível de educação, ao tipo de vinculação dessas instituições e às modificações administrativoburocráticas dos órgãos estatais.

Durante a década de 1990, o MEC realizou várias atividades envolvendo a participação de várias pessoas da sociedade com o intuito de construir uma nova concepção para a educação de crianças de zero (0) a seis (6) anos. Nesse período, vários documentos foram elaborados que enfocaram a questão da qualidade na Educação Infantil, dentre eles: 1) Estatuto da Criança e do Adolescente (BRASIL, 1990), em seu artigo $4^{\circ}$, reforça o direito ao atendimento às crianças de zero (0) a cinco (5) anos em creches e pré-escolas; 2) Lei de Diretrizes e Bases da Educação Nacional - LDBEN (BRASIL, 1996), onde surgiu uma concepção de Educação Infantil vinculada ao sistema educacional como um todo; além disso, essa lei define as formas de organização para o atendimento às crianças de até cinco (5) anos de idade e orienta o princípio do direito à educação.

Na LDBEN (BRASIL, 1996) é evidenciada a necessidade de considerar a criança como um todo para promover seu desenvolvimento, onde a responsabilidade é compartilhada com a família, a comunidade e o poder público. Outro ponto é a questão da avaliação na Educação Infantil, que deve ser utilizada com o objetivo de diagnosticar e acompanhar, sem promoção ou retenção.

Em 1998, elaborou-se o Referencial Curricular Nacional para a Educação Infantil (BRASIL, 1998). Esse documento constitui a primeira proposta curricular oficial destinada à faixa etária de zero (0) a cinco (5) anos. Em 1999, houve a aprovação das Diretrizes Curriculares Nacionais para a Educação Infantil (Resolução nº. 1, de 07 de abril de 1999) pelo Conselho Nacional de Educação (CNE/CEB), onde se estabelece que todos os sistemas de ensino municipais e estaduais de educação deviam ter como fundamentos essas diretrizes em seus projetos político-pedagógico. Esse documento foi revogado pela Resolução $\mathrm{CNE} / \mathrm{CEB}$ $\mathrm{n}^{\circ} .5$, de 17 de dezembro de 2009.

E no início do século XXI, ou seja, no ano 2000, foram elaboradas as Diretrizes Operacionais para a Educação Infantil, que correspondem ao Parecer $n^{\circ} .4$ do CNE/CEB, de 16 de fevereiro de 2000, o qual relata a vinculação das instituições de Educação Infantil ao sistema de ensino. Em 2002, ocorreu a instituição das Diretrizes Curriculares Nacionais para a 
Formação de Professores da Educação Básica (Resolução nº 1, CNE/CP, 18 de fevereiro de 2002), em nível superior, curso de licenciatura, de graduação plena, reforçando a qualificação mínima para a docência na Educação Infantil.

Já em 2006, foi elaborado o documento Parâmetros Nacionais de Qualidade para Educação Infantil, no qual encontramos um mapeamento detalhado das ações políticas desenvolvidas pelo governo federal. E por último, em 2009, a Resolução nº. 5, de 17 de dezembro de 2009, fixa as novas Diretrizes Curriculares Nacionais para a Educação Infantil, e a Emenda Constitucional $n^{\circ}$. 59, aprovada no Congresso Nacional em 11 de novembro de 2009, institui a obrigatoriedade escolar para as crianças a partir de quatro (4) anos de idade.

Diante da história da Educação Infantil, percebe-se uma profunda ligação do atendimento às crianças com o assistencialismo, uma vez que a função professor muitas vezes confunde-se com a função materna, mas não há como negar o cuidado marcante dos profissionais que atuam com crianças de zero a cinco anos, apesar de isso ser conflituoso para alguns profissionais (FACHINETTI; NASCIMENTO; GIROTO, 2016).

Os contextos apresentados no Brasil, sobre o atendimento à criança em idade para frequentar as instituições de Educação Infantil, são resultados de vários tipos de iniciativas e efetivados no meio de diversas concepções de criança. Ao longo dessa trajetória, podemos observar como os resultados de novas políticas educacionais começaram a delinear a Educação Infantil em nosso país.

Com todos esses documentos e processos de mudanças, o governo busca a universalização da Educação Infantil, bem como a produção de impactos positivos no ensino fundamental pela obrigatoriedade da frequência na pré-escola.

\section{Acessibilidade e o Processo de Inclusão do Público-Alvo da Educação Especial na Educação Infantil em Manaus/AM}

Com base no estudo de Manzini e Corrêa (2014), bem como discutido na dissertação de Souza (2017), verificamos que a nomenclatura acessibilidade está sendo muito utilizada no momento atual por diferentes representantes da nossa sociedade, sejam eles políticos, pesquisadores e até mesmo pessoas leigas, porém, nem sempre o termo acessibilidade é compreendido da mesma forma por esses indivíduos.

Governantes tendem a usar a palavra de forma bastante generalizada, cujo conceito servirá aos objetivos políticos. As pessoas leigas tentam apreender esse conceito por aquilo que está na mídia. O pesquisador deve tomar 
cuidado para não reproduzir o conceito que está na mídia, na internet e em livros sem antes promover uma análise crítica sobre o conteúdo da definição (MANZINI; CORRÊA, 2014).

Neste trabalho, utilizamos o conceito de acessibilidade definido na Lei $\mathrm{n}^{\circ}$. 13.146, de 6 de julho de 2015 (BRASIL, 2015), também conhecida como Lei Brasileira de Inclusão da Pessoa com Deficiência ou Estatuto da Pessoa com Deficiência, onde acessibilidade é definida como:

[...] possibilidade e condição de alcance para utilização, com segurança e autonomia, de espaços, mobiliários, equipamentos urbanos, edificações, transportes, informação e comunicação, inclusive seus sistemas e tecnologias, bem como de outros serviços e instalações abertos ao público, de uso público ou privados de uso coletivo, tanto na zona urbana como na rural, por pessoa com deficiência ou com mobilidade reduzida (BRASIL, 2015)

Manzini e Corrêa (2014) chamam a atenção de alguns pontos na definição de acessibilidade, para que de forma científica possamos compreender os fragmentos que se apresentam nesse conceito.

O primeiro ponto que podemos analisar é que a acessibilidade, segundo a definição apresentada, é uma possibilidade e condição. Essa possibilidade e condição é para a utilização dos espaços, mobiliários, equipamentos urbanos, edificações, transportes, informação e comunicação, inclusive seus sistemas e tecnologias, bem como de outros serviços e instalações abertos ao público (MANZINI; CORRÊA, 2014).

Ainda sobre os termos "possibilidade" e "condição", esses não devem ser desenvolvidos de qualquer forma, mas sim, com segurança e autonomia, autonomia esta que deve ser total (certa independência) ou assistida (necessita de apoio) (MANZINI; CORRÊA, 2014).

E o último ponto que levamos em consideração é o público-alvo da acessibilidade, que seriam as pessoas com deficiência e mobilidade reduzida, mas claro que, relembrando os conceitos de desenho universal já apresentados neste texto, podemos ampliar como público todas as pessoas da sociedade, tendo em vista que o desenho universal tem como base o reconhecimento da diversidade humana (MANZINI; CORRÊA, 2014).

Outro ponto importante da temática é discutir a questão conceitual dos termos acesso e acessibilidade, termos que ainda causam muita confusão teórica e conceitual, para isso, utilizaremos os ensaios teóricos de pesquisadores renomados e vistos como referências em nosso país (MANZINI, 2005; 2015; MANZINI; CORRÊA, 2014). 
O sentido do termo acesso pode ser o de entrar em qualquer lugar ou vincular-se a determinada atividade. Pode ter o significado de conseguir obter uma informação. Pode significar sair de um nível e ingressar em outro: ingresso no mercado de trabalho, ingresso no ensino superior. Por outro lado, o vocábulo "acessibilidade" relaciona-se com requisitos materiais e reais, os quais podem ser avaliados, normatizados e exigidos por lei (MANZINI, 2005; 2015; MANZINI; CORRÊA, 2014).

Buscando analisar a situação do processo de inclusão dos alunos público-alvo da educação especial, ou seja, alunos com deficiências, transtornos globais do desenvolvimento e altas habilidades/superdotação na rede municipal de educação de Manaus, apresentamos os dados coletados através da solicitação realizada junto à Secretaria Municipal de Educação da Cidade de Manaus/AM, da lista de escolas onde então matriculados educandos com deficiência no ensino regular da cidade de Manaus.

Assim, apresentamos dados da Secretaria Municipal de Educação - SEMED/Manaus, com o quantitativo de alunos incluídos nos Centros Municipais de Educação Infantil ou em escolas dos anos iniciais do ensino fundamental que ofertam a Educação Infantil nos anos de 2014 e 2016.

Quadro 1 - Alunos incluídos

\begin{tabular}{|c|c|c|c|}
\hline \multicolumn{5}{|c|}{ QUANTITATIVO DE ALUNOS INCLUÍDOS (SEMED/MANAUS) } \\
\hline Público-Alvo da Educação Especial & $\mathbf{2 0 1 4}$ & $\mathbf{2 0 1 6}$ & Total \\
\hline Autismo Infantil & 26 & 113 & $\mathbf{1 3 9}$ \\
\hline Baixa Visão & 2 & 10 & $\mathbf{1 2}$ \\
\hline Cegueira & 1 & 2 & $\mathbf{3}$ \\
\hline Deficiência Auditiva & 3 & 6 & $\mathbf{9}$ \\
\hline Deficiência Física & 9 & 40 & $\mathbf{4 9}$ \\
\hline Deficiência Intelectual & 49 & 117 & $\mathbf{1 6 6}$ \\
\hline Deficiência Múltipla & 12 & 11 & $\mathbf{2 3}$ \\
\hline Transtorno Desintegrativo da Infância & 1 & 7 & $\mathbf{8}$ \\
\hline Altas Habilidades/Superdotação & 0 & 1 & $\mathbf{1}$ \\
\hline Asperger & 0 & 10 & $\mathbf{1 0}$ \\
\hline Surdez & 0 & 3 & $\mathbf{3}$ \\
\hline Rett & 0 & 2 & $\mathbf{2}$ \\
\hline Total & 103 & 322 & $\mathbf{4 2 5}$ \\
\hline
\end{tabular}

Fonte: Relação de Alunos Incluídos (SEMED, 2014; 2016). Nota: Dados Trabalhados pelos autores.

Conforme dados apresentados na tabela, a SEMED/Manaus identificou os educandos público-alvo da Educação Especial em dez categorias, sendo que as quatro últimas só 
começaram a ser indicadas a partir do ano de 2016, a saber, Altas Habilidades/Superdotação, Asperger, Surdez e Rett.

No total, identificamos 425 alunos matriculados na Educação Infantil (Creche e PréEscola) na Rede Municipal de Educação em Manaus, Amazonas, nos anos de 2014 e 2016. Nesses dois anos, os alunos com deficiência intelectual e autismo infantil permaneceram com índices elevados, possuindo 166 e 139 respectivamente.

A separação das categorias surdez e deficiência auditiva se dá pelo entendimento que no primeiro caso o aluno possui perda total da audição e, no segundo caso, um termo amplo que abarca desde a perda total, até aqueles que possuem perda leve ou moderada.

Outras subcategorias que apareceram são as que compreendem os transtornos globais do desenvolvimento, que englobam os alunos com: autismo infantil, síndrome de Asperger e Rett.

Por fim, dos alunos incluídos, os com menor participação, segundo os relatórios, são os alunos com altas habilidades/superdotação, surdez, síndrome de Rett e Cegueira, nesses casos, podemos apontar como fator decisivo a falta de identificação precoce ou mesmo a exclusão dos mesmos do espaço escolar nessa etapa educacional.

No que tange ao cenário da acessibilidade na Educação Infantil da Secretaria Municipal de Educação de Manaus (SEMED/Manaus), baseados nas publicações de Souza e Matos (2014a; 2014b), foi observado sistematicamente a realidade de dois Centros Municipais de Educação Infantil (CMEI's), a partir de coleta e registro descritivo de dados do Projeto Político-Pedagógico e mediante a aplicação de um formulário (acessibilidade física, informação e comunicação) elaborado por DISCHINGER (2009), o qual subsidiou a observação.

Com a coleta, identificamos que no CMEI 01, localizado na zona centro-sul de Manaus, existem rampas nos desníveis, porém não possui o ícone da acessibilidade, ou seja, o Símbolo Internacional de Acesso, previsto na Lei $n^{\circ} .7 .407$ de 12 de novembro de 1985 (BRASIL, 1985), onde é obrigatória a colocação de forma visível do símbolo internacional de acessibilidade nos lugares que proporcionem a entrada, movimentação e aproveitamento por pessoas com deficiência. Já no CMEI 02 não foi encontrado nada na estrutura física que possibilite a acessibilidade.

No CMEI 01, o aluno com deficiência física (usuário de cadeira de rodas) não sabia usar o bebedouro, e após uma demonstração de como se abria e fechava a torneira, o mesmo 
ficava abrindo e fechando a torneira, pois como ele não tinha a prática de beber água sozinho, em grande parte das vezes os colegas buscavam água para ele.

Outro momento observado foi durante o lanche, onde ao levar o aluno usuário de cadeira de rodas para se servir, ele ficou contente, pois também foi uma das poucas vezes que ele fez isso: por conta das dificuldades e o trabalho em levá-lo até a cozinha, a professora o deixava em uma cadeira de plástico na primeira mesa do refeitório e pegava a refeição para ele.

Outro ponto que destacamos no CMEI 01 foi quando a professora colocou o aluno com deficiência física no chão para mostrar como ele se locomovia pela escola, pois devido a dores nas costas da professora a mesma não podia carregá-lo, colocá-lo e/ou transportá-lo na cadeira de rodas.

O CMEI 01 possui rampas em algumas partes dos desníveis que existem na escola, porém apenas rampas não caracteriza a acessibilidade, pois a acessibilidade é uma condição onde o indivíduo participa de forma autônoma e ativa dos diversos espaços, onde suas particularidades são respeitadas.

Já no CMEI 02, localizado na zona leste de Manaus, não observamos nenhuma tentativa de incluir essa criança tanto no espaço físico quanto educacional e/ou pedagógico. Apenas um esforço mínimo da professora na adequação de algumas atividades, mas ela mesma relatou que sozinha não pode incluir a criança com deficiência visual, pois não tem apoio da coordenação pedagógica, nem da gestão escolar e muito menos da SEMED.

Em relação à estrutura física, o CMEI 02 é mal distribuído e organizado: existiam armários e prateleiras nos corredores estreitos, o banheiro com vários produtos químicos expostos, sem nenhum tipo de indicação tátil para facilitar a orientação de uma criança com deficiência visual, que é o caso da criança que estudava lá; comparando com a outra criança (CMEI 01), seria impossível a locomoção da criança com deficiência física nesta escola.

Não temos muito a falar sobre o cotidiano da escola pois a criança com deficiência visual estava de licença médica, já que tinha realizado uma cirurgia e no ano seguinte seria transferida para uma escola especial: na escola atual e em outras visitadas pela família, nenhuma possibilitaria a participação dela de forma total ou assistida.

Tanto no CMEI 01 quanto no CMEI 02 identificamos a lacuna existente na formação dos professores a respeito da inclusão, acessibilidade, atuação com alunos público-alvo da educação especial, conhecimento das políticas públicas inclusivas; bem como a falta de estrutura física nas escolas para que todos possam usufruir os espaços e as dificuldades e o 
assistencialismo na Educação infantil, principalmente nos educandos com deficiência e/ou mobilidade reduzida.

Em relação à formação e capacitação de professores, vimos o despreparo e falta de incentivo em dar formação continuada a essas professoras que atuam com educandos com deficiência física e ou mobilidade reduzida. Segundo a Lei de Diretrizes e Bases - LDB (Lei $n^{\circ}$. 9.394/1996), o artigo 59 determina que os sistemas de ensino assegurarão aos educandos com necessidades especiais: "I- currículos, métodos, técnicas, recursos educativos e organização especial para atender as necessidades e no III - professores capacitados para a integração/inclusão desses alunos nas classes comuns/regulares": em ambos os CMEI's isso também não está sendo respeitado.

Os dois CMEI"s não estão de acordo com o está determinado no Decreto nº .3 .298 , de 20 de dezembro de 1999 (BRASIL, 1999) e a Lei $\mathrm{n}^{\circ} .10 .098$, de 19 de dezembro de 2000 (BRASIL, 2000), que estabelecem diretrizes e especificações basilares com a intenção de efetivação da acessibilidade das pessoas com deficiência e/ou com mobilidade reduzida, tendo como referência a NBR 9050 (ABNT, 2004), que especifica regras que uniformizam os requisitos mínimos para o acesso e utilização das pessoas com deficiência, possibilitando a utilização dos meios de transporte, prédios públicos e/ou os particulares de uso coletivo, móveis utilizados pela sociedade em geral e de acessibilidade na comunicação.

Infelizmente não encontramos em nenhum dos CMEI's ações que favoreçam a acessibilidade dessas pessoas e ações de inclusão por parte da escola, muito menos em conjunto com a comunidade.

O desafio atual da educação é a inclusão de todos os educandos e/ou comunidade escolar em todos os processos, respeitando suas especificidades, caracterizando de fato a inclusão. No que se refere especificamente à Educação Infantil, vamos destacar algumas informações com base no Manual de Acessibilidade Espacial para Escolas (DISCHINGER, 2009) sobre o espaço da Educação Infantil, o trocador acessível e o parque infantil.

Os espaços da Educação Infantil, assim como os espaços de qualquer segmento educacional, devem apresentar: contraste de cor entre o piso, parede e móveis, a fim de facilitar a orientação de pessoas com baixa visão; temperatura do piso agradável em dias frios e quentes; as mesas permitirem a aproximação e utilização por quem utiliza cadeiras de rodas; prateleira de brinquedos em altura acessível para todos; espaço suficiente e adequado entre os móveis; banheiros e vasos sanitários (e acessível) em dimensões adequadas para as crianças menores. 
Os trocadores em sanitários acessíveis devem possuir: barra de apoio junto à mesa; chuveiro no ambiente acessível; barras de apoio no trocador, vestiário e próximo ao chuveiro; banco removível ou articulado; entre outras coisas.

E o último item, os parques infantis, devem apresentar: contraste de cor entre o piso e os brinquedos; piso absorvente de impactos (areia fina, grama, emborrachado, etc.); brinquedos acessíveis às crianças com deficiência; brinquedos com risco de queda (escorregador, torres, pontes, etc.) com corrimão e cercas de proteção; piso nivelado (sem degraus que atrapalhem a circulação de cadeiras de rodas) e; bancos para os acompanhantes do usuário do parque infantil.

Apesar dos diversos avanços legais e normativos no Brasil, principalmente no estado do Amazonas a situação referente à população com deficiência ainda é bastante precária, merecendo, portanto, maior atenção por parte das instituições de ensino superior, pois as pessoas com deficiência ainda hoje encontram muitas dificuldades para desempenharem suas atividades acadêmicas/escolares, haja visto o descaso em relação às normas.

\section{Considerações finais}

O conhecimento científico hoje disponível autoriza a visão de criança como sujeito do processo de educação, que desde o nascimento busca atribuir significado a sua experiência, e nesse processo volta-se para conhecer o mundo material e social, ampliando gradativamente o campo de sua curiosidade e inquietações, mediada pelas orientações, materiais, espaços e tempos que organizam as situações de aprendizagem e pelas explicações e significados a que ela tem acesso.

Cada criança apresenta um ritmo e uma forma própria de colocar-se nos relacionamentos e nas interações, de manifestar emoções e curiosidade, e elabora um modo próprio de agir nas diversas situações que vivencia desde o nascimento, conforme experimenta sensações de desconforto ou de incerteza diante de aspectos novos que lhe geram necessidades e desejos, e lhe exigem novas respostas. Assim, busca compreender o mundo e a si mesma, testando de alguma forma as significações que constrói, modificando-as continuamente em cada interação, seja com outro ser humano, seja com objetos.

Desse modo, averiguamos que existem inúmeras manifestações dos governos (federal, estadual e municipal) e um pequeno número de atuações no caminho entre implementar e efetivar as disposições garantidas em leis, que sustentam e legitimam o direito de igualdade, 
de ir e vir, de acessibilidade, de educação, bem como tantos outros benefícios previstos em diversos documentos.

Precisa-se tomar consciência da importância da implementação de políticas públicas que garantam a acessibilidade em todas as suas dimensões e se constituem em pré-requisito para um cenário social inclusivo, ou seja, uma sociedade que reconhece, respeita e responde às necessidades de todos os cidadãos.

Ser uma escola inclusiva está além do ato de inserir uma criança com deficiência na sala de aula, os aspectos físicos da escola devem ser estudados e, se for o caso, adaptados de forma que a especificidade e o acesso do aluno sejam respeitados, garantindo a permanência, do mesmo, no ambiente escolar. Para Sassaki (2004, p.1), a acessibilidade é um meio que contribui para a inclusão.

AGRADECIMENTOS: À Coordenação de Aperfeiçoamento de Pessoal de Nível Superior (CAPES).

\section{REFERÊNCIAS}

ABNT - Associação Brasileira de Normas Técnicas. NBR 9050: Acessibilidade a edificações, mobiliário, espaços e equipamentos urbanos. Rio de Janeiro, 2004.

ANDRÉ, Marli Eliza Dalmazo Afonso de. Etnografia da prática escolar. Campinas: Papirus, 1995.

BARDIN, Laurence. Análise de conteúdo. São Paulo: Edições, 2011.

BRASIL. Constituição da República Federativa do Brasil de 1988. Brasília, DF, 1998. Disponível em: http://www.planalto.gov.br/ccivil_03/constituicao/constituicao.htm. Acesso em: 10 dez. 2016.

BRASIL. Decreto N$^{\circ}$ 3.298, de 20 de dezembro de 1999. Brasília, DF, 1999. Disponível em: http://www.planalto.gov.br/ccivil_03/decreto/d3298.htm. Acesso em: 11 jul. 2018.

BRASIL. Decreto $\mathbf{N}^{\circ}$ 5.296, de 02 de dezembro de 2004. Brasília, DF, 2004. Disponível em: http://www.planalto.gov.br/ccivil_03/_ato2004-2006/2004/decreto/d5296.htm. Acesso em: 13 jul. 2018.

BRASIL. Lei $\mathbf{N}^{\circ} \mathbf{1 0 . 0 9 8}$, de 19 de dezembro de 2000. Brasília, DF, 2000b. Disponível em: http://portal.mec.gov.br/arquivos/pdf/lei10098.pdf. Acesso em: 11 jul. 2018.

BRASIL. Lei $\mathbf{N}^{\mathbf{0}}$ 13.146, de 6 de julho de 2015. Brasília, DF, 2015. Disponível em: http://www.planalto.gov.br/ccivil_03/_ato2015-2018/2015/lei/113146.htm. Acesso em: 13 jul. 2018. 
BRASIL. Lei $\mathbf{N}^{\mathbf{0}}$ 7.405, de 12 de novembro de 1985. Brasília, DF, 1985. Disponível em: http://www.planalto.gov.br/ccivil_03/leis/1980-1988/L7405.htm. Acesso em: 11 jul. 2018.

BRASIL. Lei No 8.069, de 13 de julho de 1990. Brasília, DF, 1990. Disponível em: http://www.planalto.gov.br/ccivil_03/leis/L8069.htm. Acesso em: 13 jul. 2018.

BRASIL. Lei No 9.394, de 20 de dezembro de 1996. Brasília, DF, 1996. Disponível em: http://www.planalto.gov.br/ccivil_03/leis/L9394.htm. Acesso em: 11 jul. 2018.

BRASIL. Ministério da Educação. Secretaria de Educação Básica. Projeto de cooperação técnica MEC e UFRGS para a construção de orientações curriculares para a Educação Infantil: Práticas cotidianas na Educação Infantil - Bases para a reflexão sobre as orientações curriculares. Brasília, 2009.

BRASIL. Secretaria de Educação Especial. Política Nacional de Educação Especial na Perspectiva da Educação Inclusiva. Brasília, DF, jan. 2008b. Disponível em: http:// portal.mec.gov.br/arquivos/pdf/politicaeducespecial.pdf. Acesso em: 13 jul. 2018.

DISCHINGER, Marta. Manual de acessibilidade espacial para escolas: o direito à escola acessível. Brasília: Ministério da Educação, Secretaria de Educação Especial, 2009.

FACHINETTI, Tamiris Aparecida.; NASCIMENTO, Beatriz A. Barboza do.; GIROTO, Cláudia Regina Mosca. O Trabalho pedagógico para alunos público-alvo da educação especial: investigando a inclusão na educação infantil. Revista Ibero-Americana de Estudos em Educação, v. 11, n. esp. 2, p. 861-880, 2016. Disponível em:

https://dx.doi.org/10.21723/riaee.v11.esp2.p861-880. E-ISSN: 1982-5587. Acesso em: 11 jul. 2018.

INEP - Instituto Nacional de Estudos e Pesquisas Educacionais Anísio Teixeira. Censo Escolar da Educação Básica, 2016. Brasília: MEC, 2017. Disponível em: http://download.inep.gov.br/educacao_basica/censo_escolar/notas_ estatisticas/2017/notas_estatisticas_censo_escolar_da_educacao_basica_2016.pdf. Acesso em: 13 jul. 2018.

KRAMER, Sônia (Org.). Infância e educação infantil. Campinas, SP: Papirus, 1999.

LÜDKE, Menga.; ANDRÈ, Marli Eliza Dalmazo Afonso. Pesquisa em educação: abordagens qualitativas. São Paulo: EPU, 1986. (Coleção Temas Básicos de Educação e Ensino).

MANZINI, Eduardo José. Acessibilidade: um aporte na legislação para o aprofundamento do tema na área da educação. In.: BAPTISTA, Claudio Roberto.; CAIADO, Katia Regina Moreno.; JESUS, Denise Meyrelles (Orgs.). Educação especial: diálogo e pluralidade. 3. ed. Porto Alegre: Mediação, 2015.

MANZINI, Eduardo José. Inclusão e acessibilidade. Revista da Sobama, v. 10, n. 1. p. 3136, 2005. Suplemento. 
MANZINI, Eduardo José.; CORRÊA, Priscila Moreira. Avaliação de acessibilidade na educação infantil e no ensino superior. São Carlos: Marquezine \& Manzini: ABPEE, 2014.

MARCONI, Marina de Andrade.; LAKATOS, Eva Maria. Fundamentos de metodologia científica. São Paulo: Atlas, 1993.

MINAYO, Maria Cecília de Souza. O desafio do conhecimento. São Paulo: Hucitec,1993.

SEMED - Secretaria Municipal de Educação da Cidade de Manaus. Parecer Técnico com os dados referente a matrícula dos alunos com deficiências inseridos na Rede Municipal de Ensino. SEMED: Manaus, 2014.

SEMED - Secretaria Municipal de Educação da Cidade de Manaus. Parecer Técnico com os dados referente a matrícula dos alunos com deficiências inseridos na Rede Municipal de Ensino. SEMED: Manaus, 2016.

SOUZA, Danilo Batista de.; MATOS, Maria Almerinda de Souza. Acessibilidade na Educação Infantil: um estudo em dois centros municipais de educação infantil da cidade de Manaus. In: II Congresso Nacional de Formação de Professores e XII Congresso Estadual Paulista sobre Formação de Educadores, 2014, Águas de Lindóia/SP. Anais do II Congresso Nacional de Formação de Professores e XII Congresso Estadual Paulista sobre Formação de Educadores. São Paulo: Universidade Estadual Paulista, 2014a. v. 01. p. 8778-8789.

SOUZA, Danilo Batista de.; MATOS, Maria Almerinda de Souza. Formação de Professores e Acessibilidade na Educação Infantil: os desafios para a inclusão em dois CMEI's da cidade de Manaus. In: 12a Jornada de Educação Especial: Ciência e Conhecimento em Educação Especial, 2014, Marília. Anais da 12a Jornada de Educação Especial: Ciência e Conhecimento em Educação Especial. Marília: UNESP, 2014b. v. 01. p. 01-11.

SOUZA, Danilo Batista de.; MATOS, Maria Almerinda de Souza. Acessibilidade e Inclusão Escolar de Alunos com Deficiência e/ou Mobilidade Reduzida na Escola Pública. 2017. 128 f. Dissertação (Mestrado em Educação). Faculdade de Educação, Universidade Federal do Amazonas. Manaus.

TRIVIÑOS, Augusto Nibaldo Silva. Introdução à Pesquisa em Ciências Sociais: A Pesquisa Qualitativa em Educação. São Paulo: Atlas, 1987.

\section{Como referenciar este artigo}

MATOS, Maria Almerinda de Souza.; SOUZA, Danilo Batista; OLIVEIRA, Jáima Pinheiro de. Acessibilidade e educação infantil: o processo de inclusão do público-alvo da educação especial em Manaus/AM. Revista Ibero-Americana de Estudos em Educação, Araraquara, v. $14, \quad$ n. esp. 1, p. 760-744, abr., 2019. E-ISSN: 1982-5587. DOI: 10.21723/riaee.v14iesp.1.12205

Submetido em: 06/08/2018

Aprovado em: 21/09/2018 